\title{
Aplikasi Pupuk N, P, K dan Konsorsium Pupuk Hayati terhadap Retensi Hara, Serapan, dan Hasil Kedelai (Glycine max (L.)) pada Inceptisol
}

\author{
Yuniarti Anni'1), Yuliati Machfud1), Eso Solihin'1), Yogi Sudirman ${ }^{2)}$, Apong Sandrawati1) \\ 1) Staf Pengajar Fakultas Pertanian Universitas Padjadjaran \\ 2) Alumni Program Studi Agroteknologi Fakultas Pertanian, Universitas Padjadjaran \\ Jl. Raya Bandung Sumedang Km 21 Jatinangor \\ Korespondensi: anni_yuniarti@yahoo.com
}

\begin{abstract}
Inceptisol is a widespread soil order with low fertility. Hence it is necessary to improve its quality status through the application of chemical and biological fertilizers. The main objecttive of this study is to determine the effect of NPK fertilizer and biofertlizer consortia (BC) combinations in Inceptisols towards $N$ and $P$ availability in soil and uptake by soybean (Glycine max L.). Experiments were carried out from April to August 2016 at Ciparanje Experimental Farm, Faculty of Agriculture, Universitas Padjadjaran, Jatinangor, Sumedang at the approximate altitude of 720 meters above the sea level. Randomized Block Design experimental design consisted of ten treatments and three replications was used in this study. Treatments consisted of control (no treatment), Recommended $N P K$ dosage, $0 N P K+1 B C, 1 / 4 N P K+1 B C, 1 / 2 N P K+1 B C, 3 / 4 N P K+1 B C, 1 N P K+1 B C, 3 / 4 N P K+1 / 4$ $B C, 3 / 4 N P K+1 / 2 B C$ and also $3 / 4 N P K+3 / 4 B C$. Experimental results showed that the combination of NPK fertilizer and soybean-spesific biofertilizer consortium increased soil total phosphate content, nitrogen uptake by plant, and soyben yield significantly.
\end{abstract}

Keywords: Biofertilizer, Soybean, total-N, Uptake of N, Inceptisols

\section{PENDAHULUAN}

Inceptisol adalah ordo tanah yang memiliki luasan sekitar 70,52 juta ha atau $44,60 \%$ dari potensial luas daratan Indonesia (Puslittanak, 2003) sehingga ordo ini mempunyai prospek cukup besar untuk dikembangkan sebagai usaha pertanian. Permasalahan utama yang dihadapi pada Inceptisol adalah tingkat kesuburan yang rendah dengan karakteristik $\mathrm{pH}$ agak masam dan ketersediaan unsur hara N, P, K rendah (Kasno dkk, 2006) sehingga untuk mengatasi permasalahan tersebut diperlukan upayaupaya dalam peningkatan ketersediaan hara pada tanah tersebut yang salah satunya adalah melalui pemberian pupuk anorganik.

Pemberian pupuk anorganik berupa Urea, SP-36 dan $\mathrm{KCl}$ secara intensif dapat menyebabkan tanah mengalami kerusakan sehingga diperlukannya alternatif lain untuk mengurangi penggunaannya. Kondisi tanah yang berada di Indonesia menunjukkan bahwa $90 \%$ dari 70 juta ha lahan pertanian telah terdegradasi dengan signifikan, bahkan dikategorikan sebagai lahan sakit dan kelelahan (sick and fatigue soils) akibat penggunaan pupuk anorganik yang intensif tersebut (Simarmata dkk, 2012). Salah satu upaya yang dapat dilakukan adalah dengan penggunaan pupuk hayati.

Pupuk hayati adalah inokulan berbahan aktif organisme hidup dalam bentuk cair atau padat yang memiliki kemampuan untuk memobilisasi memfasilitasi dan meningkatkan ketersediaan hara tidak tersedia menjadi bentuk tersedia melalui proses biologis (Simarmata dkk, 2012). Penggunaan pupuk hayati diharapkan mampu untuk mengurangi penggunaan pupuk anorganik, khususnya Urea dan SP-36 sehingga membantu meningkatkan kandungan $\mathrm{N}$-total di dalam tanah, serapan $\mathrm{N}$, serta meningkatkan produksi tanaman.

Kedelai (Glycine max (L.) merupakan salah satu jenis komoditi pangan yang dikonsumsi dalam jumlah yang banyak. Indonesia 
termasuk ke dalam salah satu negara penghasil kedelai dengan areal penanaman yang luas, yakni sekitar 614.095 ha (BPS, 2015). Produksi kedelai pada tahun 2013 sebesar 780,26 ribu ton biji kering atau mengalami penurunan sebesar 62,99 ribu ton (8,07\%) dibandingkan dengan tahun 2012 (BPS, 2013). Pada tahun 2014 mengalami peningkatan menjadi 953,96 ribu ton biji kering (BPS, 2014) dan pada tahun 2015 sebesar 998,87 ribu ton biji kering.

Seiring dengan peningkatan jumlah penduduk menyebabkan permintaan kebutuhan akan kedelai menjadi tinggi, yakni setiap tahunnya adalah sekitar 2.3 jutaan ton, namun kemampuan produksi kedelai nasional hanya berkisar \pm 800 ribu ton per tahun (Dirjentanpan, 2013; FAOSTAT, 2012) sehingga untuk memenuhi kekurangan kebutuhan tersebut, pemerintah harus melakukan impor karena keterbatasan produksi.

Tanaman kedelai varietas Arjasari merupakan salah satu varietas yang memiliki potensi hasil yang cukup tinggi dalam usaha peningkatan produksi kedelai, yakni berkisar 1,030-4,683 ton/ha dengan rata-rata hasilnya adalah 2,235 ton/ha (Keputusan Peraturan Menteri Pertanian, 2005). Selain itu, varietas ini juga cukup responsif terhadap pemupukan, bijinya besar dan moderat toleran terhadap genangan air serta peka terhadap serangan dari lalat kacang (Keputusan Peraturan Menteri Pertanian, 2005) sehingga sudah selayaknya varietas ini untuk dikembangkan potensinya.

\section{BAHAN DAN METODE}

\subsection{Waktu dan Tempat Penelitian}

Percobaan dilaksanakan pada bulan April sampai dengan Agustus 2016 yang terdiri atas percobaan di lapangan dan analisis unsur hara dan tanaman. Percobaan ini dilakukan di Kebun Percobaan Fakultas Pertanian Universitas Padjadjaran Kampus
Jatinangor, Kabupaten Sumedang, Jawa Barat. Analisis dilakukan di Laboratorium Kesuburan Tanah dan Nutrisi Tanaman, Fakultas Pertanian Universitas Padjadjaran Jatinangor.

\subsection{Bahan dan Alat}

Bahan yang digunakan dalam percobaan antara lain: benih kedelai (Glycine max (L.)) varietas Arjasari, media tanam berupa tanah Inceptisols, pupuk hayati, pupuk anorganik tunggal (Urea $(45 \% \mathrm{~N})$, SP-36 $\left(36 \% \mathrm{P}_{2} \mathrm{O}_{5}\right)$, dan $\left.\mathrm{KCl}\left(60 \% \quad \mathrm{~K}_{2} \mathrm{O}\right)\right)$, dan bahan-bahan yang digunakan dalam analisis di laboratorium.

Pupuk hayati yang digunakan merupakan pupuk hayati yang dibuat khusus untuk tanaman kedelai (Pupuk Hayati Khusus Kedelai (PHKK)). Hasil analisis terhadap kandungan pupuk hayati yang digunakan dalam percobaan adalah warna pupuknya coklat hitam, pH-nya 5,7, kandungan $\mathrm{N}$ dan $\mathrm{K}_{2} \mathrm{O}$-nya $1,0 \%, \mathrm{P}_{2} \mathrm{O}_{5}$-nya 2,0 \%, C-organiknya $20,5 \%, \mathrm{C} / \mathrm{N}$ rasionya 21 serta bakteri penambat $\mathrm{N}$ dan pelarut P-nya adalah $10,4 \mathrm{x}$ $10^{7} \mathrm{CFU} / \mathrm{g}$. Hasil analisis menunjukkan bahwa pupuk hayati yang digunakan pada percobaan sudah memenuhi persyaratan teknis minimal pupuk hayati majemuk yang ditetapkan pupuk hayati yang ditetapkan oleh Permentan No 70 Tahun 2011.

Alat yang digunakan selama percobaan yaitu : polibeg volume $10 \mathrm{~kg}$, sekop kecil, timbangan analitik, penggaris dan jangka sorong, alat tulis, emrat, dan alat-alat yang digunakan untuk analisis laboratorium, seperti: labu didih, erlenmeyer, alat destilasi, mesin kocok, tabung reaksi, dll.

\subsection{Rancangan Percobaan}

Rancangan yang digunakan adalah Rancangan Acak Kelompok (RAK), yang terdiri atas 10 kombinasi perlakuan (Tabel 1). Rincian dari perlakuan tersebut adalah delapan perlakuan diantaranya menggunakan dosis Pupuk Hayati Khusus Kedelai (PHKK) serta 1 perlakuan dosis pupuk rekomendasi 
dan 1 sebagai kontrol sebagai pembanding untuk melihat pengaruhnya terhadap tanaman kedelai.

Pengamatan respon yang dilakukan terdiri atas pengamatan utama yang dianalisis statistik dan pengamatan penunjang yang tidak dianalisis statistik. Pengamatan utama terdiri atas: a. Analisis kandungan unsur hara berupa $\mathrm{N}$, dan $\mathrm{P}$ tanah dan tanaman. Sampel diambil pada saat fase vegetatif maksimum

b. Hasil kedelai; bobot kering biji per tanaman dan dikonservasikan dalam bobot biji kering per hektar.

Tabel 1 Susunan Perlakuan Kombinasi Pupuk N,P,K dan Konsorsium Pupuk Hayati

\begin{tabular}{|c|c|c|c|c|c|}
\hline \multirow{2}{*}{ Kode } & \multirow{2}{*}{ Perlakuan } & \multirow{2}{*}{$\begin{array}{l}\text { Pupuk Hayati } \\
\text { (g.Ha-1) }\end{array}$} & \multicolumn{3}{|c|}{$\begin{array}{c}\text { Takaran Pupuk NPK } \\
\left(\text { Kg.Ha }^{-1}\right)\end{array}$} \\
\hline & & & Urea & SP-36 & $\mathrm{KCl}$ \\
\hline A & Kontrol & 0 & 0 & 0 & 0 \\
\hline B & NPK Standar & 0 & 75 & 100 & 100 \\
\hline $\mathrm{C}$ & 0 NPK + 1 PHKK & 250 & 0 & 0 & 0 \\
\hline $\mathrm{D}$ & 1/4 NPK + 1 PHKK & 250 & 18,75 & 25 & 25 \\
\hline E & $1 / 2 \mathrm{NPK}+1$ PHKK & 250 & 37,5 & 50 & 50 \\
\hline $\mathrm{F}$ & 3/4 NPK + 1 PHKK & 250 & 56,25 & 75 & 75 \\
\hline G & $1 \mathrm{NPK}+1$ PHKK & 250 & 75 & 100 & 100 \\
\hline $\mathrm{H}$ & $3 / 4$ NPK + 1/4 PHKK & 62,5 & 56,25 & 75 & 75 \\
\hline I & $3 / 4 \mathrm{NPK}+1 / 2$ PHKK & 125 & 56,25 & 75 & 75 \\
\hline $\mathrm{J}$ & $3 / 4$ NPK + 3/4 PHKK & 187,5 & 56,25 & 75 & 75 \\
\hline \multicolumn{6}{|c|}{ Keterangan : } \\
\hline
\end{tabular}

\subsection{Analisis Data}

Data hasil pengamatan diuji dengan uji $\mathrm{F}$ untuk mengetahui adanya perbedaan respons terhadap pertumbuhan dan produktivitas tanaman kedelai dari setiap perlakuan yang selanjutnya, dilakukan uji stastistika lanjutan dengan menggunakan Uji Jarak Berganda Duncan pada taraf $5 \%$.

\section{HASIL DAN PEMBAHASAN}

\subsection{Analisis Tanah Awal}

Hasil analisis tanah awal Inceptisol Jatinangor menunjukkan bahwa tanah yang digunakan memiliki $\mathrm{pH}$ yang agak masam, yakni 6,32, kandungan C-organik rendah $(1,86$ $\%)$, N-Total sedang $(0,28 \%)$, Rasio $\mathrm{C} / \mathrm{N}$ rendah (7), serta $\mathrm{P}_{2} \mathrm{O}_{5}$ tersedia juga rendah $(13,41 \mathrm{mg} / \mathrm{kg})$ dan $\mathrm{P}_{2} \mathrm{O}_{5}$ potensial sedang (39,27 cmol. $\left.\mathrm{Kg}^{-1}\right)$, kandungan $\mathrm{K}_{2} \mathrm{O}$ tergolong sedang $\left(25,38 \mathrm{cmol} . \mathrm{Kg}^{-1}\right)$.

Kapasitas Tukar Kation (KTK) tanah awal tergolong tinggi $\left(33,6 \mathrm{cmol} \mathrm{Kg}^{-1}\right)$ dengan kejenuhan basa yang juga tinggi $(63,21 \%)$. Pada Kation dapat ditukar, berturut-turut hasil dari analisisnya adalah K-dd tinggi $(0,92$ cmol. $\left.\mathrm{Kg}^{-1}\right)$, Na-dd rendah $(0,34)$, Ca-dd sangat tinggi $\left(10,67 \mathrm{cmol}^{\mathrm{Kg}}{ }^{-1}\right)$, Mg-dd tinggi $(9,31$ cmol. $\mathrm{Kg}^{-1}$ ). Pada tanah ini untuk teksturnya adalah tergolong liat berdebu dengan fraksi pasir $8 \%$, liat $41 \%$ dan debu $51 \%$.

Berdasarkan hasil analisis tersebut, Inceptisol Jatinangor memiliki tingkat kesuburan dan kandungan hara yang cukup 
rendah. Hal ini ditunjukkan terutama dengan kandungan $\mathrm{C}$-organik yang rendah serta $\mathrm{N}$ Total tanah sedang sehingga diperlukan pemupukan. Pupuk yang diberikan antara lain, pupuk kompos pada pra-tanam serta kombinasi pupuk $\mathrm{N}, \mathrm{P}, \mathrm{K}$ dan pupuk hayati khusus kedelai (PHKK) saat budidaya berlangsung.

\subsection{Kadar N dan P tanah}

Perlakuan PHKK tidak berpengaruh nyata terhadap N-total tanah. Berdasarkan klasifikasinya, N-total dalam tanah pada semua perlakuan berada pada kriteria sedang (Tabel 2). Nilai N-total setelah perlakuan juga tidak berbeda nyata dengan hasil analisis awal $(0,28 \%)$ dengan kriteria $\mathrm{N}$-total sedang. Salah satu faktor yang mempengaruhi kandungan $\mathrm{N}$-total tanah adalah tekstur tanah. Nilai Ntotal tanah akan lebih tinggi pada tanah dengan tekstur lebih halus (Najmadeen, 2011).

Tabel 2 Pengaruh aplikasi pupuk N,P,K dan korsosium pupuk hayati terhadap Ntotal tanah

\begin{tabular}{ccc}
\hline $\begin{array}{c}\text { Kode } \\
\text { Perlakuan }\end{array}$ & $\begin{array}{c}\text { N-total tanah } \\
(\%)\end{array}$ & Kriteria* \\
\hline A & $0,22 \mathrm{a}$ & Sedang \\
B & $0,25 \mathrm{a}$ & Sedang \\
C & $0,29 \mathrm{a}$ & Sedang \\
D & $0,30 \mathrm{a}$ & Sedang \\
E & $0,30 \mathrm{a}$ & Sedang \\
F & $0,21 \mathrm{a}$ & Sedang \\
G & $0,27 \mathrm{a}$ & Sedang \\
H & $0,31 \mathrm{a}$ & Sedang \\
I & $0,27 \mathrm{a}$ & Sedang \\
J & $0,28 \mathrm{a}$ & Sedang
\end{tabular}

Keterangan: Angka rerata yang diikuti huruf yang sama menunjukkan bahwa tidak memberikan pengaruh yang nyata berdasarkan Uji Jarak Berganda Duncan $5 \%$

* : Berdasarkan Puslitanak (1983)

Nilai N-total tanah yang tidak berbeda nyata dapat dipengaruhi oleh sumber bahan organik. Widowati dan Hartatik (2007) menyatakan bahwa jenis bahan organik dapat mempengaruhi kadar $\mathrm{N}$-total dalam tanah. Pada penelitian ini, sumber bahan organik yang diberikan sebagai perlakuan adalah sama. Nilai $\mathrm{N}$-total yang tidak berbeda nyata juga dapat disebabkan oleh sifat $\mathrm{N}$ yang mobil dan volatil (Roosmarkam dan Yuwono, 2002).

Hasil analisis statistik untuk nilai $\mathrm{P}$ dan $\mathrm{K}$ total dapat dilihat pada Tabel 3. Perlakuan pupuk N-P-K dan konsorsium hayati memberikan pengaruh, namun tidak nyata. Hal ini dapat dilihat dari notasi yang hanya dibedakan menjadi a dan ab. Nilai P total $(\mathrm{HCl}$ 25\%) setelah perlakuan meningkat secara signifikat jika dibandingkan dengan pengukuran pada tanah awal. Nilai kadar $\mathrm{P}$ pada tanah awal adalah sebesar $39,27 \mathrm{cmol}$. $\mathrm{Kg}^{-1}$ dengan kategori sedang, sedangkan kadar P-total setelah perlakuan $58-60 \mathrm{cmol} \mathrm{Kg}^{-1}$ atau berada pada kriteria tinggi sampai sangat tinggi.

Tabel 3 Pengaruh aplikasi pupuk N,P,K dan korsosium pupuk hayati terhadap kadar P dan K tanah

\begin{tabular}{ccc}
\hline $\begin{array}{c}\text { Kode } \\
\text { Perlakuan }\end{array}$ & $\begin{array}{c}\text { P-HCl 25\% } \\
\left(\mathrm{mg} . \mathrm{Kg}^{-1}\right)\end{array}$ & Kriteria* \\
\hline $\mathrm{A}$ & $59,18 \mathrm{a}$ & Tinggi \\
$\mathrm{B}$ & $61,06 \mathrm{ab}$ & Sangat Tinggi \\
$\mathrm{C}$ & $58,41 \mathrm{a}$ & Tinggi \\
$\mathrm{D}$ & $64,67 \mathrm{ab}$ & Sangat Tinggi \\
$\mathrm{E}$ & $66,70 \mathrm{ab}$ & Sangat Tinggi \\
$\mathrm{F}$ & $59,86 \mathrm{a}$ & Tinggi \\
$\mathrm{G}$ & $62,15 \mathrm{ab}$ & Sangat Tinggi \\
$\mathrm{H}$ & $69,10 \mathrm{~b}$ & Sangat Tinggi \\
I & $60,05 \mathrm{a}$ & Sangat Tinggi \\
J & $61,41 \mathrm{ab}$ & Sangat Tinggi \\
\hline
\end{tabular}

Keterangan: Angka rerata yang diikuti huruf yang sama menunjukkan bahwa tidak memberikan pengaruh yang nyata berdasarkan Uji Jarak Berganda Duncan $5 \%$

* : Berdasarkan Puslitanak (1983)

Peningkatan P-total tanah sangat dipengaruhi oleh pemupukan. Selain pupuk N$\mathrm{P}-\mathrm{K}$ yang menjadi sumber utama, 
penambahan pupuk hayati dinilai dapat meningkatkan P-total dalam tanah. Nurmayulis (2014) menyatakan bahwa Fosfat dalam tanah sebagian besar dalam bentuk terfiksasi oleh koloid liat tanah, dan terikat dengan kation logam seperti $\mathrm{Al}^{3+}, \mathrm{Fe}^{3+}, \mathrm{Mn}^{2+}$ dan $\mathrm{Mn}^{3+}$. Penambahan pupuk hayati dapat mengubah bentuk tidak tersedia $\mathrm{P}$ menjadi tersedia bagi tanaman (Mahdi et. al., 2010). Asam organik mampu untuk menurunkan $\mathrm{pH}$ dan mampu melarutkan fosfat yang terikat dengan kation-kation logam.

\subsection{Kadar N dan P tanaman}

Serapan hara tanaman merupakan jumlah hara yang diserap oleh tanaman serta masuk kedalam jaringan tanaman, dan diperoleh berdasarkan hasil analisis jaringan tanaman. Pada Tabel 4 menunjukan hasil analisis statistik kandungan serapan $\mathrm{N}, \mathrm{P}$, dan $\mathrm{K}$ tanaman. Hasil analisis menunjukan perbedaan yang nyata antara perlakuan pemberian PHKK terhadap serapan N dan P.

Tabel 4 Pengaruh aplikasi pupuk N,P,K dan Korsosium pupuk hayati terhadap Rata-rata N dan P tanaman Kedelai

\begin{tabular}{ccc}
\hline $\begin{array}{c}\text { Kode } \\
\text { Perlakuan }\end{array}$ & $\begin{array}{c}\text { N-total } \\
\text { tanaman } \\
(\%)\end{array}$ & $\begin{array}{c}\text { P-total } \\
\text { tanaman } \\
\left(\% \mathrm{P}_{2} \mathrm{O}_{5}\right)\end{array}$ \\
\hline $\mathrm{A}$ & $43,23 \mathrm{abc}$ & $0,20 \mathrm{a}$ \\
$\mathrm{B}$ & $50,25 \mathrm{cde}$ & $0,22 \mathrm{ab}$ \\
$\mathrm{C}$ & $41,25 \mathrm{ab}$ & $0,21 \mathrm{a}$ \\
$\mathrm{D}$ & $47,54 \mathrm{bcd}$ & $0,23 \mathrm{ab}$ \\
$\mathrm{E}$ & $44,51 \mathrm{abc}$ & $0,22 \mathrm{~b}$ \\
$\mathrm{~F}$ & $37,52 \mathrm{a}$ & $0,22 \mathrm{ab}$ \\
$\mathrm{G}$ & $44,52 \mathrm{abc}$ & $0,21 \mathrm{ab}$ \\
$\mathrm{H}$ & $57,62 \mathrm{e}$ & $0,25 \mathrm{~b}$ \\
$\mathrm{I}$ & $55,10 \mathrm{de}$ & $0,22 \mathrm{ab}$ \\
J & $53,83 \mathrm{de}$ & $0,21 \mathrm{ab}$ \\
\hline
\end{tabular}

Keterangan: Angka rerata yang diikuti huruf yang sama menunjukkan bahwa tidak memberikan pengaruh yang nyata berdasarkan Uji Jarak Berganda Duncan $5 \%$
Hasil serapan tertinggi diperoleh sebesar $57,62 \%$ pada perlakuan $\mathrm{H}(3 / 4 \mathrm{NPK}+1 / 4$ PHKK) dan berbeda nyata dibandingkan dengan perlakuan kontrol. Tingginya serapan $\mathrm{N}$ pada tanaman umumnya dipengaruhi oleh adanya akumulasi $\mathrm{N}$ pada jaringan tanaman. Pemupukan dengan urea dan proses fiksasi $\mathrm{N}$ oleh bakteri akan meningkatkan asimilasi $\mathrm{N}$ pada tanaman sehingga pada akhirnya dapat meningkatkan kandungan $\mathrm{N}$ pada daun, bobot tanaman serta biji (Situmorang, 2008).

Pengaruh N,P, dan $\mathrm{K}$ dengan kombinasi PHKK terhadap serapan $\mathrm{P}$ tanaman juga menunjukan hal yang berbeda nyata. Perlakuan $\mathrm{H}(3 / 4$ NPK $+1 / 4$ PHKK $)$ menujukan nilai tertinggi dalam meningkatkan serapan $\mathrm{P}$ pada tanaman dengan jumlah serapan sebanyak 0,25\% namun tidak berbeda nyata jika dibandingkan dengan perlakuan E $(1 / 2 \mathrm{NPK}+1$ PHKK) denagan nilai serapan sebanyak $0,22 \%$.

Berdasarkan uraian di atas, dapat dinyatakan bahwa dosis 3/4 NPK + 1/4 PHKK dapat memebrikan hasil serapan tertinggi pada tanaman kedelai. Namun, serapan $\mathrm{P}$ tertinggi terdapat pada dosis $1 / 2 \mathrm{NPK}+1$ PHKK dan $1 / 2$ NPK +1 PHKK. Hal ini dapat dipertimbangkan dalam penelitian selanjutnya.

\subsection{Hasil Panen Kedelai}

Berdasarkan hasil analisis ragam pada Tabel 5, pemberian kombinasi perlakuan pupuk N,P,K dan konsorsium pupuk hayati mampu memberikan pengaruh yang nyata jika dibanding dengan kontrol terhadap bobot biji kedelai per hektar. Perlakuan E (1/2 NPK + 1 PHKK) merupakan perlakuan terbaik dibandingkan perlakuan lainnya dengan rata-rata bobot biji tertinggi senilai 2,32 ton/ha, meskipun apabila dilihat dari uji statistik hasilnya tidak berbeda nyata dengan perlakuan $\mathrm{D}$ dan $\mathrm{H}$.

Peningkatan hasil bobot biji per hektar berkaitan dengan pertumbuhan ataupun 
perkembangan dari organ vegetatif tanaman karena apabila unsur hara mencukupi maka dapat berbanding lurus dengan perkembangan organ generatif juga. Selain itu, menurut Zainal dkk (2014) hasil bobot biji per hektar juga dipengaruhi oleh banyaknya jumlah daun yang tumbuh karena semakin banyaknya cahaya yang ditangkap, maka proses fotosintesis akan meningkat sehingga potensi asimilat hasil proses tersebut akan ditranslokasikan ke biji.

Tabel 5 Pengaruh aplikasi pupuk N,P,K dan Korsosium pupuk hayati terhadap Rata-rata Rata-rata Berat 100 Biji Kedelai dan hasil per Ha

\begin{tabular}{ccc}
\hline $\begin{array}{c}\text { Kode } \\
\text { Perlakuan }\end{array}$ & $\begin{array}{c}\text { Rata-rata } \\
\text { berat 100 biji } \\
\text { (g) }\end{array}$ & $\begin{array}{c}\text { Rata-rata } \\
\text { (ton/ha) }\end{array}$ \\
\hline $\mathrm{A}$ & $13,53 \mathrm{a}$ & $0,73 \mathrm{a}$ \\
$\mathrm{B}$ & $16,06 \mathrm{ab}$ & $1,24 \mathrm{bcd}$ \\
$\mathrm{C}$ & $15,34 \mathrm{ab}$ & $1,15 \mathrm{~b}$ \\
$\mathrm{D}$ & $20,73 \mathrm{~cd}$ & $2,24 \mathrm{~g}$ \\
$\mathrm{E}$ & $21,53 \mathrm{~d}$ & $2,32 \mathrm{~g}$ \\
$\mathrm{~F}$ & $17,20 \mathrm{bc}$ & $1,67 \mathrm{de}$ \\
$\mathrm{G}$ & $21,05 \mathrm{~cd}$ & $1,83 \mathrm{ef}$ \\
$\mathrm{H}$ & $20,91 \mathrm{~cd}$ & $2,15 \mathrm{fg}$ \\
$\mathrm{I}$ & $18,75 \mathrm{bc}$ & $1,53 \mathrm{cde}$ \\
$\mathrm{J}$ & $17,56 \mathrm{bc}$ & $1,35 \mathrm{bc}$ \\
\hline Keterangan : Angka yang diikuti huruf yang sama \\
& $\begin{array}{c}\text { menunjukkan bahwa tidak memberikan } \\
\text { pengaruh yang nyata berdasarkan Uji }\end{array}$ \\
& Jarak Berganda Duncan 5\%
\end{tabular}

\section{KESIMPULAN}

Kombinasi pupuk N,P,K dan konsorsium hayati dapat memberikan pengaruh meningkatkan $\mathrm{N}, \mathrm{P}, \mathrm{K}$ tanah dan $\mathrm{N}, \mathrm{P}, \mathrm{K}$ tanaman serta hasil tanaman kedelai Inceptisol Jatinangor. Perlakuan $1 / 4 \mathrm{~N}, \mathrm{P}, \mathrm{K}+1$ PHKK merupakan perlakuan terbaik apabila ditinjau dari efisiensi penggunaan pupuk dalam peningkatan terhadap hasil tanaman kedelai dengan bobot biji konversi senilai 2,24 ton/ha.

\section{DAFTAR PUSTAKA}

Badan Pusat Statitiska. 2013. Produksi Sayuran dan Buah-Buahan Semusim di Indonesia, 1997-2012. Tersedia : www.bps.go.id. Diakses 04 Juni 2016

Badan Pusat Statistika. 2014. Berita Resmi Statistik. Tersedia: http://bps.go.id/Bps/view /id/1122. Diakses 04 April 2016

Badan Pusat Statistika. 2015. Berita Resmi Statistik. Tersedia : https://bps.go.id/Bps $\quad / v i e w / i d .1122$. Diakses 04 April 2016

Direktorat Jenderal Tanaman Pangan (Dirjentanpan). 2013. Pedoman Teknis Pengelolaan Produksi Kedelai Tahun 2013.. Kementerian Petanian. Jakarta.

FAOSTAT. 2012.2 Database. http://faostat.fao.org/site/339/default .aspx. Diakses 17 Juni 2016

Hartatik, W dan Widowati, L.R. 2007. Pupuk kandang dalam Pupuk Organik dan Pupuk Hayati. Balai Besar Penelitian dan Pengembangan Sumberdaya Lahan Pertanian. Bogor.

Kasno, A., D. Setyorini, dan E. Tuberkih. 2006. Pengaruh pemupukan fosfat terhadap produktivitas tanah Inceptisol dan Ultisol. Jurnal Ilmu-Ilmu Pertanian Indonesia.Vol 8 No. 2 : 91 - 98.

Keputusan Peraturan Menteri Pertanian. 2005. Pelepasan Kedelai Varietas Arjasari. Tersedia : http://perundangan.pertanian.go.id/a dmin/file/SK-520-05.pdf. Diakses 19 Juni 2016

Mahdi, S.S., G.I. Hassan, S.A. Samoon, H.A. Rather, A.D. Showkat, B. Zehra. 2010. Bio-ferlizer in organic agriculture (review article). Journal of Phytology 2(1): $42-54$. 
Najmadeen, H.H. 2011. Effects of soil organic matter, total nitrogen and texture on nitrogen mineralization process. Journal of Al-Nahrain University 14(2); $144-151$.

Roosmarkam, A dan Yuwono, N.W. 2002. Ilmu Kesuburan Tanah. Kanisius. Yogyakarta.

Simarmata, T., B. Joy dan N. Danapriatna. 2012. Peranan Penelitian dan Pengembangan Pertanian Pada Industri Pupuk Hayati Biofertilizers. Fakultas Pertanian Universitas Padjadjaran.

Situmorang, A.R.F. 2008. Penggunaan inokulan B. japonicum toleran asam alumunium untuk pertumbuhan tanxah kedelai pada tanah masam [Skripsi]. FMIPA IPB, Bogor.

Zainal, M., Agung Nugroho dan Nur Edy Suminarti. 2014. Respon pertumbuhan dan hasil tanaman kedelai (Glycine max (L.) Merrill) pada berbagai tingkat pemupukan $\mathrm{N}$ dan pupuk kandang ayam. Jurnal Produksi Tanaman 2(6): 484 -490. 